REVIEW S.

Outlines of Scientific Anatomy. By Wilhelm Lubosch, Professor of Anatomy in Würzburg. Translated from the German by H. H. Woollard, M.D. Professor of Anatomy, University of Adelaide.

This book has been written "for students of biology and medicine, designed to supplement the usual textbook teaching."

We cannot conceive that any student would, firstly, understand this book; and, secondly, that it would help him as regards his normal curriculum. It is deeply philosophical, and in places almost unintelligible. This is probably in no small measure due to the fact that the translation from the German is very nearly literal in character. The net result is that the work is only suited for ultra-scientific minds, and cannot be recommended for students. We quote the following sentence which occurs in the paragraph discussing the relation of life to its component parts :-

"The contradictions have distant similarities with the antinomies of Kant, rooted perhaps in the same opposites which were significant in the antinomies." We believe

\section{ST. PETER'S HOSPITAL for stone, \&c.,}

Henrietta St., Coyent Garden, W.C.2.

A Post-Graduate Course (fee five guineas) will be held from 8th to 20th April, 1929. Full syllabus will be forwarded on application to the undersigned.

BEECHEY ROGERS, Secretary.

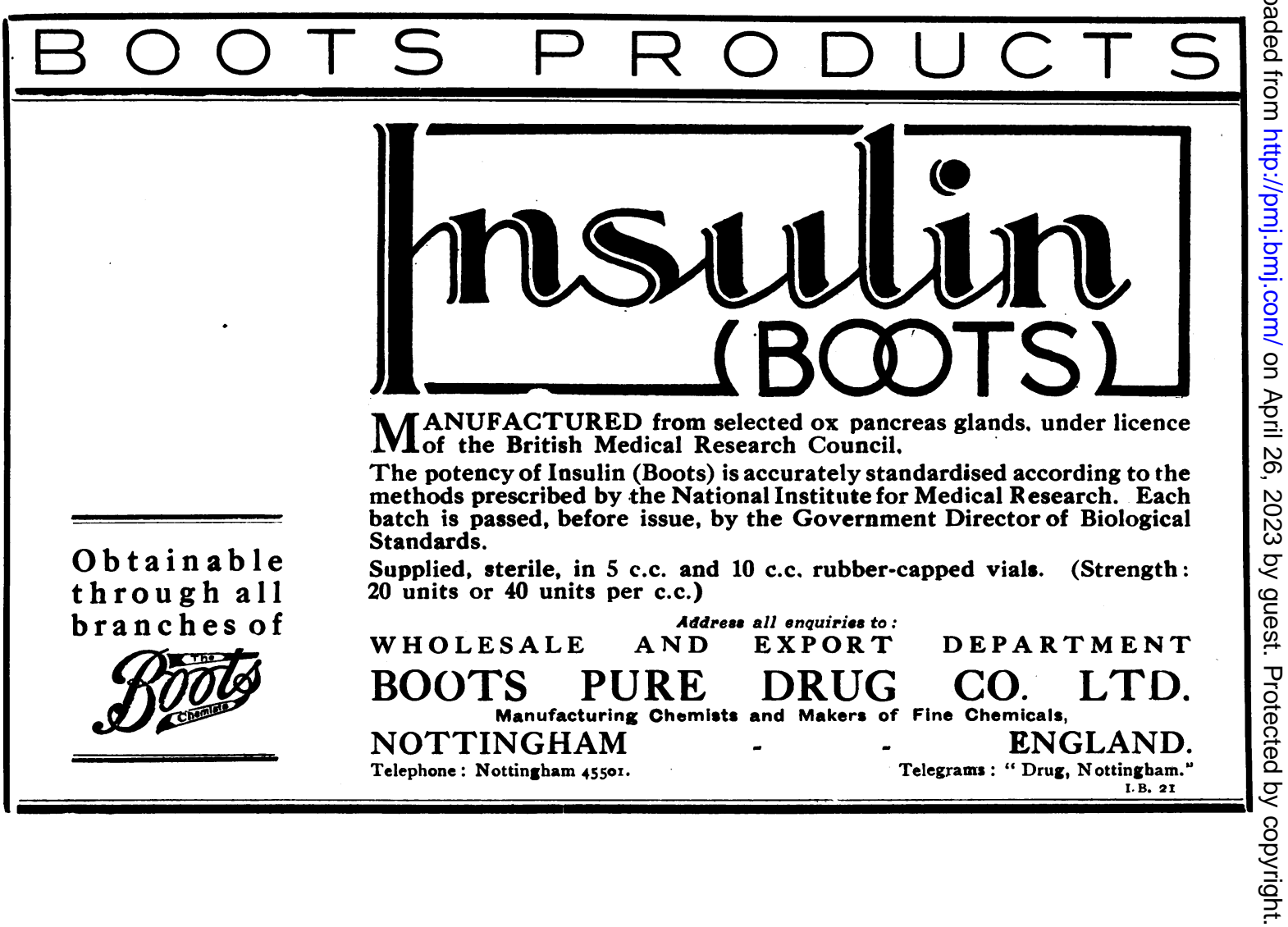


that a student reading a sentence such as this, and many others of a similar character, would either change his profession, or at least look upon anatomy as a counsel of despair. In short, while this book is probably of considerable interest to those well versed in the doctrines and teachings of philosophy, we feel that the average medical student starting anatomy would be hopelessly lost in attempting to correlate it with his routine medical work.

Medical AdVenture. SOME EXPERIences of a General Praciutioner. By Ernest Ward, M.D., F.R.C.S. 1929. London : John Bale, Sons and Danielsson. Pp. 29r. Price 8s. 6d.

This very readable little book will give great pleasure to many. It consists of a number of papers, some of which have previously been published in various medical journals. The author has a wide experience, and his chapters deal with such divergent subjects as "An Evening with the Spirits" and the "Tale of a Wayside Inn," "Legal Adventures," and "Mumps."

There is a great deal of very sound advice and useful information on many matters which must frequently puzzle a busy practitioner, and Dr. Ward is to be congratulated on a delightful work dealing both with the human and scientific side of medical practice.

Manson's Tropical Diseases. Edited by Philip H. Manson-Bahr, M D., F.R.C.P. Physician to the Hospital for Tropical Diseases, London, \&c., London: Cassell and Co., Ltd. Ninth Edition. 1929. Pp. 92 I. Price 3Is. $6 \mathrm{~d}$.

This book is so well known that a new edition is always welcome. Several new illustrations have been added, and the whole $\frac{2}{3}$ work has been brought up to date.

Perhaps the most interesting part of the $\stackrel{c}{.}$ new edition is that dealing with recent $\stackrel{\vec{F}}{\vec{P}}$ advances in treatment, especially; as the editor points out, in malaria, kala-azar, $\frac{\bar{c}}{\bar{c}}$ dysentery and sprue. But in all subjects $\frac{\bar{\sigma}}{\vec{\sigma}}$

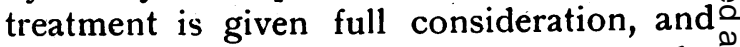
not merely relegated to a few lines at the ${ }^{\infty}$ end of lengthy descriptions of pathological $\vec{\circ}$ changes as is so frequently the case in text- $\vec{\omega}$ books on medicine.

The general arrangement of the book is $\frac{0}{3}$ similar to that of the previous editions, and ${ }_{+}$. the editor has succeeded in adding a large $\frac{\dot{\omega}}{\omega}$ amount of new material without appreciably increasing the size of the book.

The appendix is divided into two parts, $\overrightarrow{>}$ the first dealing with medical zoology, and으․ the second with laboratory methods.

The book concludes with a very $\operatorname{good} \mathbb{U}_{0}$ index.

We beg to remind our readers that a sub- $\frac{\overrightarrow{0}}{3}$ scription of ten shillings per annum entitles? them to become Members of the Fellowship of Medicine. Every Member gets this Journalo post free for the year of his subscription, and he also receives any "Special Announce ments" of lectures, demonstrations, \&c., taking place at the various hospitals, generalo and special. Subscription for the Journals only is $6 \mathrm{~s}$. per annum.

Intending members should apply to the Secretary of the Fellowship of Medicinew (Room 28), I, Wimpole Street, W.I, either sending their subscription of ten shillings or asking for a Bankers' Order. 